\title{
Demand for household sanitation in India using NFHS-3 data
}

\author{
Anurag N. Banerjee ${ }^{1}$. Nilanjan Banik ${ }^{2}$. \\ Ashvika Dalmia ${ }^{1}$
}

Received: 23 February 2016 / Accepted: 14 February 2017 / Published online: 3 April 2017

(C) The Author(s) 2017. This article is an open access publication

\begin{abstract}
India has the highest number of people defecating in the open, and the Indian Government is trying to eradicate by constructing toilets for its citizens. This paper is about whether the government is likely to succeed in its cleanliness drive mission by a supply-side policy. We examine the household preference and other the factors leading to open defecation in India. We examine preference for having a toilet in the household over the preference of other household durable goods. Our results suggest toilets get a lower preference-ranked 12, out of 21 different types of consumer durables we investigate. The results also indicate a strong case for imparting education and public awareness, especially, among the female cohort. We find the odds of having toilets in a household with an educated woman (18years of schooling) is 3.1 times more than a household with illiterate or preschool educated women. Among other factors households living in urban areas are 19 times more likely to have toilets in comparison with their rural counterparts.
\end{abstract}

Keywords India $\cdot$ Toilets $\cdot$ Preference ranking

JEL Classification C01 $\cdot$ I18 · O 11

$\triangle$ Anurag N. Banerjee

a.n.banerjee@durham.ac.uk

1 Durham Business School, Durham, UK

2 Bennett University, Greater Noida, India 


\section{Introduction}

\subsection{Background}

On 2 October 2014, the Indian Prime Minister Mr. Narendra Modi launched the Swachh Bharat (Clean India) mission, aimed at creating a 'Clean India' over the next 5 years. The mission is a response to the rising perception about Indian cities as not being clean. This, unfortunately, is true to a certain extent. In the rural areas, only 32.70 of rural households have access to toilets. Over $40 \%$ of government schools in India do not have a functioning toilet. On a global scale, India has the highest number of people defecating in the open, at a staggering number of 597 million (WHO and UNICEF 2014). In 2012, the average concentration of open defecate per square kilometre area was highest in India that was more than double of the world average (Coffey et al. 2014). Each day, about 100,000 tons of human faeces are found in the open (UNICEF 2012).

Through Swachh Bharat mission, the government plans to build 110 million toilets across the country between 2014 and 2019. The success, however, is conditional upon toilets being delivered, and more importantly, that there will be takers. In fact, when the government allocates money for developmental activities such as education, health, and sanitation, it has to prioritize its spending, ideally in a fashion so that a sector with a higher social return gets more funding relative to the others. In this case, returns from constructing toilets will be higher provided people start using toilets and stops defecating in the open.

Given the policy focus on the supply-side economics of toilet construction, we ask the question as to how the households private value the construction of toilets vis-avis the accumulation of other consumer durables. This paper addresses this important aspect and characterizes household's decision to construct toilets within their household.

\subsection{Preference for a household toilet}

In terms of household preference, we compare the demand for toilets vis-à-vis 20 other aspirational consumer durables, such as cots, watches, mattresses, chairs, bicycles, tables, electric fans, televisions, pressure cookers, radios, motorcycles, water pumps, mobile telephones, telephones (fixed), sewing machines, refrigerators, tractors, animal-drawn carts, threshers, and computers. We also examine preference structure for using toilets among residents from various states in India. In this way, we can comment about the state-wise difference in toilet coverage that is determined by cultural factors (exogenous) or the lack of sanitation related infrastructure (endogenous) for example, availability of water in the household.

This study takes into account the first large data set-Demographic and Health Survey (DHS) data collected in 2005-2006. The Indian version of the DHS data, that is, the third round of the National Family and Health Survey (NFHS-3), contains information about use of toilets by various household characteristics, namely gender, religion, area, and geography. 
Our results suggest that for any individual building toilets gets a far lower preference among lists of other household durable goods. Toilets are ranked at 12, out of 21 different types of consumer durables, considered for this study. Regional (state-level) ranking reveals that the north-eastern part of the country and Kerala (a southern state in India) has a higher preference for toilets compared to other durables. The northern and western states have worse rankings.

When the analysis is done conditioning on other socio-economic characteristics, in terms of odds ratio of having a toilet (prob(toilet)/prob(notoilet)), we found that a household in which a woman has attained higher education (18 years of schooling) is 3.1 times more likely to have toilets. Geographically, households living in urban areas are 19 times more likely to have toilets in comparison with their rural counterparts. Religion and caste (religious subdivisions) plays a role as well. The effect of religion shows that Muslim households are 5.4 times more likely to adopt a toilet than a Hindu household is. Even Christian households are 1.3 times more likely to adopt a toilet in comparison with their Hindu counterparts. Hindu households have lowest coverage of sanitation facilities in comparison with other religions.

The rest of the article is organized as follows. In Sect. 2, we discuss related literature on sanitation. In Sect. 3, we describe the data and discuss preliminary statistics. In Sect. 4, we develop our empirical methodology and discuss results from our analysis. Section 5 concludes the article with relevant policy prescription.

\section{Related literature}

Swachh Bharat mission is not one-of-a-kind sanitation and hygiene interventions. In 1986, the government launched Central Rural Sanitation Programme (CRSP), giving incentives in the form of full or partial funding to households for building toilets. However, this supply-driven programme met with a limited success. Banerjee and Mandal (2011) show between 1981 and 2001, the average yearly expansion of toilet was a meagre 1\%. Later, CRSP inculcated a demand driven approach. Launched in 1999, and titled Total Sanitation Campaign (TSC), the programme emphasized more on Information, Education and Communication (IEC), human resource development, and capacity development activities, to increase awareness about better sanitation practices among rural households. Subsequently, in 2003, the government also launched Nirmal Gram Yojana (Clean Village Campaign) providing monetary incentives to Gram Panchayats (political subdivisions comprising of multiple small villages), non-profit organizations (NPOs) and economic agents, assisting toilet coverage in villages. Unfortunately, this effort too met with limited success. Reports (Shah et al. 2013) indicated that over $40 \%$ of the funds under TSC, especially those allocated under IEC remained unused, and the government subsidies were often unavailable to households which needed them the most.

There are case based studies which have looked at reasons for limited success of 'Clean India' mission. Ramani (2008) attributes this to market failure. For a poor person, the short-term opportunity cost of constructing a toilet is high since there are no short-term benefits. The poor care less about long-term health impact of sanitation compared to the everyday survival instincts. From the supply side, con- 
struction of toilets are undertaken by non-profit organizations (NPOs) which are particularly driven by their organizational aims rather than by market incentives. In addition to these demand and supply-side factors, a study undertaken by J-PAL (2012) attributes institutional constraint as a factor. For instance, constructing a closed drainage system requires coordination between centre, states, and municipalities/gram panchayats at the local-level-the latter among these are sometime not forthcoming.

In a study covering 300 households in four villages of Jalpaiguri district, West Bengal, Hazra and Dutta (2016) find good condition of toilets induces the members to reduce open defecation. According to this study, availability of water, absence of seepage, strong roof and walls, proper functioning doors with handles, etc. are important factors, and implicitly brings into focus the critical availability of masons and plumbers at village level, who are required to correct construction defects and clogging of the existing toilets. Spears (2012) finds that a reason for Indian defecating in the open is because of unavailability of improved sanitation facilities.

There are also cultural issues. Coffey et al. (2014) find that in rural northern India there is a definite preference for defecating in the open. In a survey covering 3235 households spreading across five north Indian states-Bihar, Rajasthan, Uttar Pradesh, Madhya Pradesh and Haryana-results indicate that in spite of having toilets, over $40 \%$ of the households practiced open defecation. Having a household latrine is widely seen to damage the purity of the home. Open defecation, on the other hand, is widely seen to promote purity and strength and is also associated with health and longevity. Many more in India's rural belts felt that it was pleasurable, comfortable and convenient to defecate in the open. They find it hard to break this decade hold habit and had in some cases converted toilets into a small store room. ${ }^{1}$

In a survey covering households from rural Himachal Pradesh and West Bengal, O'Reilly and Louis (2014) find successful adoption of toilet is conditioned upon three factors. First is the political will to govern so that the toilets are delivered and also to mobilize an awareness programme to educate the citizens about the benefits of using toilets. Second is the peer pressure, arising from social stigma of defecating in the open, when everyone else in the neighbourhood is using toilets. Third is the political ecology arising from the government bodies guaranteeing supply of water, and ecological factors such as soil quality-makings some areas better suited for building toilets than the others.

Ghosh and Cairncross (2014) find very large discrepancies in use of toilets between different parts of India. There is a need to study the reasons for these differences in demand for toilets pan India. This paper does that. To our knowledge, this study is the first scientific attempt deriving demand for toilets vis-à-vis other consumer durables. Additionally, we control for other factors such as gender, geography, religion/caste, institution, female empowerment, wealth and standard of living, which might influence the demand for toilets.

\footnotetext{
1 Available at: http://timesofindia.indiatimes.com/city/bareilly/UP-villagers-prefer-open-fields-razeSwachh-loos/articleshow/50582495.cms. (Accessed on 24th August 2016).
} 


\section{Description of data}

We have used NFHS-3 data collected in 2005-2006. NFHS-3 survey interviewed $1,09,041$ households spreading across 28 states in India. Information about 1,08,933 are found and are reported in Table 1. Administered under Ministry of Health and Family Welfare, Government of India, NFHS-3 collected information on women and children about health, family welfare, and nutritional intake. Throughout the analysis, household is the unit of measurement.

Regarding the use of in-house toilet, the survey asked the following question (Question Number 31): 'What kind of toilet facility do members of your households usually use?' (IIPS and Macro International, 2007c, p.48). Respondents were asked to choose among the following options: (a) Flush or pour flush toilet—piped sewer, septic tank, pit latrine, flush to somewhere else; (b) Pit latrine_-ventilated improved pit/biogas; pit latrine with slab; without slab, open pit; (c) Twin pit/composting toilet; (d) Dry toilet; and (e) No facility. We construct our Toilet variable as zero when there is no toilet facility, and one if there is any facility. We realise that just having a toilet in the household does not mean that all the household members use the toilet facility. Indeed, Hazra and Dutta (2016) show only $11.11 \%$ (out of a sample of 300 households) use household toilets and do not defecate in the open. In this research, we consider toilet as an aspirational durable good and compare it with owning other durable goods. In this fashion, we differentiate between usage and ownership of a household toilet, just like any other durable good.

In accordance with the DHS methodology, missing values for categorical items (for example, source of drinking water) were not reassigned and were treated as 'non available (NA)' observations. Missing values for dichotomous variables (for example, electricity and durable goods) were assigned to the category of failure, that is, the household does not possess these goods. Table 1 reports the summary statistics of the variables that we use for our empirical analysis.

Table 2 presents a preliminary analysis of the conditional probability of a household's access to toilet given various characteristics. This was done using simple contingency table analysis. Our conditional probability estimates in Table 2 suggest that adoption of toilets is considerably low among households residing in rural areas (0.613). People who are economically poor usually do not have toilets $(0.727$ for $k a c$ cha house). ${ }^{2}$ Culturally, Hindu households have a lower propensity to adopt a toilet (0.441). On the contrary, households who are economically better-off (having computers, televisions, and motorcycles) and have access to bank accounts, have a larger proportion of toilets in their houses. So, we need to analyse the household preference of having toilets in relation to other durable goods conditional on the level of wealth. We have done this in the next section.

\footnotetext{
2 A kaccha house is a building made of natural materials such as mud, grass, bamboo, thatch or sticks and is therefore a short-lived structure.
} 
Table 1 Summary statistics of the variables

\begin{tabular}{|c|c|c|c|c|c|}
\hline & \multirow[t]{2}{*}{ Sample total } & \multicolumn{2}{|c|}{ Latrine users } & \multicolumn{2}{|c|}{ Non-latrine users } \\
\hline & & Number & $\%$ of group & Number & $\%$ of group \\
\hline Total sample & 108,939 & 67,483 & 61.95 & 41,456 & 38.05 \\
\hline \multicolumn{6}{|l|}{ Type of residence } \\
\hline Rural & 58,753 & 22,713 & 38.66 & 36,040 & 61.34 \\
\hline Urban & 50,186 & 44,770 & 89.21 & 5416 & 10.79 \\
\hline \multicolumn{6}{|c|}{ Households highest education level } \\
\hline $\begin{array}{l}\text { No education/ } \\
\text { preschool }\end{array}$ & 9088 & 2586 & 28.46 & 6502 & 71.54 \\
\hline Primary & 15,859 & 5856 & 36.93 & 10,003 & 63.07 \\
\hline Secondary & 59,940 & 37,180 & 62.03 & 22,760 & 37.97 \\
\hline Higher & 24,038 & 21,853 & 90.91 & 2185 & 9.09 \\
\hline \multicolumn{6}{|l|}{ Household heads gender } \\
\hline Male & 93,246 & 57,933 & 62.13 & 35,313 & 37.87 \\
\hline Female & 15,693 & 9550 & 60.86 & 6143 & 39.14 \\
\hline \multicolumn{6}{|l|}{ Household heads religion } \\
\hline Hindu & 79,941 & 44,681 & 55.89 & 35,260 & 44.11 \\
\hline Muslim & 13,341 & 10,033 & 75.20 & 3308 & 24.80 \\
\hline Christian & 10,037 & 8552 & 85.20 & 1485 & 14.80 \\
\hline Other & 5592 & 4200 & 75.11 & 1392 & 24.89 \\
\hline \multicolumn{6}{|l|}{ Household has electricity } \\
\hline Yes & 85,766 & 61,931 & 72.21 & 23,835 & 27.79 \\
\hline No & 23,173 & 5552 & 23.96 & 17,621 & 76.04 \\
\hline \multicolumn{6}{|l|}{ Households wealth } \\
\hline Owns house & 91,445 & 53,684 & 58.71 & 37,761 & 41.29 \\
\hline $\begin{array}{l}\text { Owns } \\
\text { agricultural land }\end{array}$ & 43,850 & 20,803 & 47.44 & 23,047 & 52.56 \\
\hline $\begin{array}{l}\text { Owns a bank or } \\
\text { post office account }\end{array}$ & 49,253 & 38,324 & 77.81 & 10,929 & 22.19 \\
\hline \multicolumn{6}{|l|}{ House type } \\
\hline $\begin{array}{l}\text { Kachcha } \\
\text { (mud/bamboo } \\
\text { house) }\end{array}$ & 11,355 & 3102 & 27.32 & 8253 & 72.68 \\
\hline Semi-pucca & 39,590 & 16,568 & 41.85 & 23,022 & 58.15 \\
\hline Pucca (Brick house) & 57,215 & 47,300 & 82.67 & 9915 & 17.33 \\
\hline
\end{tabular}

\section{Empirical methods and results}

The empirical analysis is presented in two parts. Firstly, we examine the preference for having toilets vis-à-vis other consumer durables. Secondly, we look at various household characteristics, including, preference structure for having toilets across residents from various states. 
Table 2 Conditional probabilities for open defecation

\begin{tabular}{|c|c|}
\hline Attributes & Conditional probabilities \\
\hline \multicolumn{2}{|l|}{ Living standards attributes } \\
\hline $\operatorname{Pr}($ Open defecation-has computer $)$ & 0.018 \\
\hline $\operatorname{Pr}($ Open defecation—has car) & 0.024 \\
\hline $\operatorname{Pr}($ Open defecation-has refrigerator) & 0.064 \\
\hline $\operatorname{Pr}($ Open defecation—has mobile telephone $)$ & 0.065 \\
\hline $\operatorname{Pr}($ Open defecation—has motorcycle/scooter $)$ & 0.123 \\
\hline $\operatorname{Pr}($ Open defecation-has television) & 0.188 \\
\hline $\operatorname{Pr}($ Open defecation- - has radio $)$ & 0.241 \\
\hline $\operatorname{Pr}($ Open defecation-has electricity) & 0.278 \\
\hline $\operatorname{Pr}($ Open defecation-has bicycle $)$ & 0.393 \\
\hline \multicolumn{2}{|l|}{ Wealth attributes } \\
\hline $\operatorname{Pr}($ Open defecation—-has a bank or post office account) & 0.222 \\
\hline $\operatorname{Pr}($ Open defecation-owns this or other house) & 0.413 \\
\hline $\operatorname{Pr}($ Open defecation—owns land usable for agriculture) & 0.526 \\
\hline $\operatorname{Pr}($ Open defecation-house is pucca) & 0.173 \\
\hline $\operatorname{Pr}($ Open defecation-house is semi-pucca) & 0.582 \\
\hline $\operatorname{Pr}($ Open defecation-house is kaccha) & 0.727 \\
\hline \multicolumn{2}{|l|}{ Cultural attributes } \\
\hline $\operatorname{Pr}($ Open defecation—head of household is Muslim) & 0.248 \\
\hline $\operatorname{Pr}($ Open defecation-head of household is Hindu) & 0.441 \\
\hline $\operatorname{Pr}($ Open defecation—urban residence $)$ & 0.108 \\
\hline $\operatorname{Pr}($ Open defecation-rural residence) & 0.613 \\
\hline
\end{tabular}

\subsection{Wealth threshold and preference for toilet}

For the first part of the analysis, we create a wealth/asset index. The motivation is to examine importance of toilets vis-à-vis other major components of consumer durables. Although DHS provides a wealth index, but the constituents of this wealth index are consumer durables alongside with toilets. Bonu and Kim (2009) use this wealth index as an independent variable. Although they use a large data set obtained from the 60th round of National Sample Survey (January-June 2004), a limitation in their methodology arises from toilets featuring both as dependent and independent variables which leads to problems of endogeneity.

We define wealth in the conventional sense, as net stock of financial and real assets that are appreciating over time. OECD (2013) considers immovable property such as house, savings in banks, and land ownership as components of wealth. One obvious problem with the data we have is that we do not know the market value of these assets. Filmer and Pritchett (2001), uses the principal factor of PCA to construct the wealth index, but their methodology suffers from the usual problem of interpreting the PCA weights, which tries to orthogonalise the variance covariance matrix, assuming that the 
component variance is finite. The variance is a good measure of "spread" for symmetric distributions, but it fails when we consider skewed or asymmetric distributions. PCA tries to maximize the variance in the projected dimension. If the distribution follows Pareto distribution (in case of wealth), then variance drops quickly. This happens because as $\alpha$ (the tail-index) grows, then the data start to group around the small mean. At times, large swings are associated with the Pareto distribution, something that a small variance would not describe well. So, we construct a simple model to implicitly price the assets based on holding observables assuming the underlying Wealth is distributed $\operatorname{Pareto}(\alpha)$ :

Let $P_{a}$ be the price of the non-divisible asset $a$. Suppose, individual $i$ with disposable income $I_{i}$ buys this asset. Then, we must have $P_{a} \leq I_{i}$. Therefore, the proportion of that asset any individual has is given as:

$$
\operatorname{Pr}\left(P_{a} \leq I_{i}\right)=1-F_{I}\left(P_{a}\right)=p_{a}
$$

where $F_{I}$ is the disposable income distribution of the population.

From above, we have $P_{a}=F_{I}^{-1}\left(1-p_{a}\right)$. If the disposable income is Pareto distributed, that is, $F_{I}(P)=1-\underline{I} P^{-\alpha}$, then

$$
P_{a}=\underline{I} p_{a}^{-1 / \alpha}
$$

Here, $I$ is the threshold for minimum level of consumption.

Note that even if $F_{I}$ is not Pareto, $P_{a}$ and $p_{a}$ are negatively related.

$$
\frac{\mathrm{d} P_{a}}{\mathrm{~d} p_{a}}=-\frac{1}{f_{I}\left(P_{a}\right)}<0
$$

Here, $f_{I}\left(p_{a}\right)$ is the density function. Thus higher is the market value, the lower is the likelihood of having the assets.

With this idea, we create an asset index comprising of various assets, $a_{1}, a_{2}, \ldots, a_{N}$ that any household is likely to have, with probabilities $p_{1}, p_{2}, \ldots, p_{N}$, respectively. The probabilities are empirically estimated taking the proportion of assets in the sample. The wealth for any household $i$ is given as the weighted average of assets that the household hold $I\left(a_{i k}\right), \ldots, I\left(a_{i N}\right)$, where the weights are inversely proportional to the probabilities of the assets ownership.

$$
\text { Wealth }_{i}=\sum_{n=1}^{N} \frac{I\left(a_{i k}\right)}{p_{n}}
$$

where $I\left(a_{i n}\right)=1$, if household $i$ holds the asset $n$, zero otherwise.

We consider whether the household has a house and the types of house Kaccha $\left(K_{H} o_{i}\right)$ and Pucca $\left(P H o_{i}\right)$, bank savings accounts $\left(\right.$ Bank $\left._{i}\right),{ }^{3}$ and land $\left(\right.$ Land $\left._{i}\right)$, as components of wealth following (OECD 2013). Note that the magnitude of this wealth

\footnotetext{
3 Although we do not have any data regarding the amount of money in the accounts.
} 
index is not a nominal variable but ordinal, therefore monotonic transformations will not change the ordering (See Eq. 2).

Given a level of expected wealth, we compute the conditional probabilities with which any household is likely to own any particular consumer durable. The parameters of the probability function are estimated using maximum likelihood method of estimation. We compute the odds ratio as:

$$
\log \frac{\widehat{q}^{g}}{1-\widehat{q}^{g}}=\widehat{\beta_{0}^{g}}+\widehat{\beta_{1}^{g}} \text { Wealth }_{i} .
$$

Odds ratio gives the likelihood that a consumer will prefer any particular consumer durable. We then compute the threshold wealth level for which the probability of adopting a particular durable good is $q^{g}=0.5$. Thus, for a particular durable good $g$, the threshold level of wealth is given as

$$
\widehat{W e a l t h}^{g}=\widehat{-\beta_{0}^{g} / \beta_{1}^{g}}
$$

We estimate these 21 different probability functions with respect to the wealth, and using (4), we compute the thresholds. Finally, we rank them to determine demand for toilets in comparison with 20 other consumer durables by ordering these goods according to their thresholds. Lower is the threshold wealth, the higher is the preference for having that consumer durables. In other words, the better the rank of a toilet in a household's wealth preference ordering, the lower is the level of wealth it will be adopted. Since the wealth index is not nominal but ordinal, any monotonic transformation will preserve this ordering.

\section{Results}

Using the methodology described in Sect. 4.1, we rank households demand for toilets.

The findings gives an idea of the households' preference ranking with respect to other consumer durables. Table 3 indicates toilets get a lower preference-ranked 12 out of 21 different types of consumer durables that we investigated. Demand to have televisions and motorcycles both ranks higher than toilets. It means that these two items are more likely to be adopted at a lower level of wealth before toilets. A limitation of this data is that it is relatively old (NFHS-3 was implemented in 20052006). A newer data set is most likely to reveal mobile phones getting a better rank than toilets. A lower ranking of toilets indicates that the problem of sanitation in India is not solely determined by the supply-side factors. Thus supply-side government policy such as construction of toilets is unlikely to succeed, and a proper policy might requires behavioural alterations. This will help develop market for toilets (O'Reilly and Louis 2014).

Accounting for cultural, social, educational and infrastructural differences across India, we also map how toilets will be adopted across various states in India (See Table 4). Our results indicate Kerala and north-eastern states have a higher preference for toilets. This is consistent with the analysis by Ghosh and Cairncross (2014) and Bonu and Kim (2009) who finds that access to toilets are highest among the 
Table 3 All India ranking: preference for toilets ranked by Wealth Index

\begin{tabular}{ll}
\hline Rank & Other durable goods \\
\hline 1 & Cot/bed \\
2 & Watch \\
3 & Mattress \\
4 & Chair \\
5 & Bicycle \\
6 & Table \\
7 & Electric fan \\
8 & Television \\
9 & Pressure cooker \\
10 & Radio \\
11 & Motorcycle/scooter \\
$\mathbf{1 2}$ & Toilet \\
13 & Water pump \\
14 & Mobile telephone \\
15 & Telephone (non-mobile) \\
16 & Sewing machine \\
17 & Refrigerator \\
18 & Tractor \\
19 & Animal-drawn cart \\
20 & Thresher \\
21 & Computer \\
\hline & \\
&
\end{tabular}

north-eastern states. North-eastern states and Kerala are educationally better-off in comparison with rest of India. Female empowerment is also higher. For example, communities such as the Nairs and Ezhavas in Kerala, and the Khasi, Jaintias, and the Garo tribes in Meghalaya (comprising majority of the population) practice matriarchy, where women have power in activities relating to allocation, exchange, and production.

Consistent with Coffey et al. (2014) find that in northern and north-west India, there is a definite preference for defecating in the open. In our ranking analysis, Bihar (rank 8), Madhya Pradesh (rank 11), Haryana (rank 12), Maharashtra (14), Uttar Pradesh (rank 15), Rajasthan (rank 18) are some of the worst performers in using toilets. Cultural differences matter. For example, villagers in tribal areas in northern and West Indian states are not used to the practice of using toilets. For them, to relieve inside four walls of toilets are like defecating in the house. In fact, these villagers use toilets for 
Table 4 Regional (state-wise) preference for toilets

\begin{tabular}{lc}
\hline State & Ranking \\
\hline India & 12 \\
Arunachal Pradesh & 1 \\
Manipur & 2 \\
Assam & 2 \\
Kerala & 2 \\
Nagaland & 3 \\
Tripura & 3 \\
Sikkim & 4 \\
Mizoram & 5 \\
West Bengal & 5 \\
Meghalaya & 6 \\
Goa & 7 \\
Bihar & 8 \\
Andhra Pradesh & 8 \\
Uttaranchal & 9 \\
Gujarat & 10 \\
Delhi & 11 \\
Jammu \& Kashmir & 11 \\
Orissa & 11 \\
Madhya Pradesh & 11 \\
Karnataka & 12 \\
Himachal Pradesh & 12 \\
Punjab & 12 \\
Haryana & 12 \\
Chhattisgarh & 12 \\
Maharashtra & 14 \\
Tamil Nadu & 15 \\
Uttar Pradesh & 15 \\
Jharkhand & 18 \\
Rajasthan & \\
\hline & 12 \\
\hline
\end{tabular}

storage purpose (storing valuables) as government built toilets are the only concrete structure they had in the house. ${ }^{4}$

\subsection{Controlling for other household characteristics}

In the second part of the analysis, we control for other household characteristics which might influence the probability of toilet ownership at a household-level. We estimate

\footnotetext{
4 Available at: http://timesofindia.indiatimes.com/city/pune/In-rural-areas-newly-built-toilets-too-prettyto-use/articleshow/53472232.cms (Accessed on 20th August 2016).
} 
a logit model, controlling for various household characteristics, namely gender, age, religion/caste, area, institution, and geography which are proxies for cultural differences in a vast country like India.

Gender Jenkins and Curtis (2005) and Santos et al. (2011) argue that since there is an element of safety and dignity associated with it, women are more likely to adopt a toilet in comparison with their male counterparts.

Age Santos et al. (2011) find younger respondents in Salvador and Brazil prefer to have toilets in comparison with their older cohorts. Accordingly, we use age as a variable. Geography Bonu and Kim (2009) find regional factors such as state-level toilets intake, and urban-rural residence as factors, affecting uptake in toilet usage. To account for the region specific effect, we differentiate respondents from urban and rural areas. Within urban areas, we differentiate between mega cities, large cities, small cities, large towns, and small towns. Rural residence is taken to be the base category.

Religion/caste Bonu and Kim (2009) show the importance of religion and caste. Hence, we control for religion and caste factors. Hindu religion and general category caste are taken as the base.

Institution A study by J-PAL (2012) shows the importance of including institutional factors. We consider percentage of household in any particular state with water connection as a proxy for institution. This factor also serves as a proxy for network/demonstration effect as well. Proximity or in-house water connection is necessary to encourage households to use toilets (Banerjee and Banik 2014).

Female empowerment has been proxied by the level of female literacy and the sex of the household head. Using 2011-Census data (survey conducted by Government of India), Ghosh and Cairncross (2014) find an inverse relation between female literacy rates and open defecation. Wei et al. (2004) reports a similar finding-female literacy rates explain $24.3 \%$ of the variance in the ownership of household toilets. We take into consideration different levels of female literacy, with base level being taken as preschool or illiterate, and the higher level was constructed using data related to primary, secondary and higher education (post-secondary) levels.

Wealth Wealth is an important indicator of economic well-being so we use the wealth index $E$ Wealt $h_{i}$ that we created earlier (See, Eq. 3). In addition to the wealth index, we also include the amount of agricultural land a household owns to indicate the level of wealth in the rural area. This is to adjust against higher house prices of urban households who may not have agricultural land.

Standard of Living Index To aggregate the effect of other consumer durables and their relative preference to toilets, we create a standard of living index. We use 20 durable goods (other than toilets) $d_{1}, d_{2}, \ldots, d_{20}$ that any household is likely to have, with probabilities $q_{1}, q_{2}, \ldots, q_{20}$, respectively. The Standard of Living Index for any household $i$ is given as $S L I_{i}=\sum_{l=1}^{20} d_{i, l} / q_{l}$. Figure 1 shows the empirical distribution of the standard of living index. It is a skewed distribution, with a majority population having a lower standard of living.

Finally, regional specific variation is captured by introducing state-specific dummy variables. 


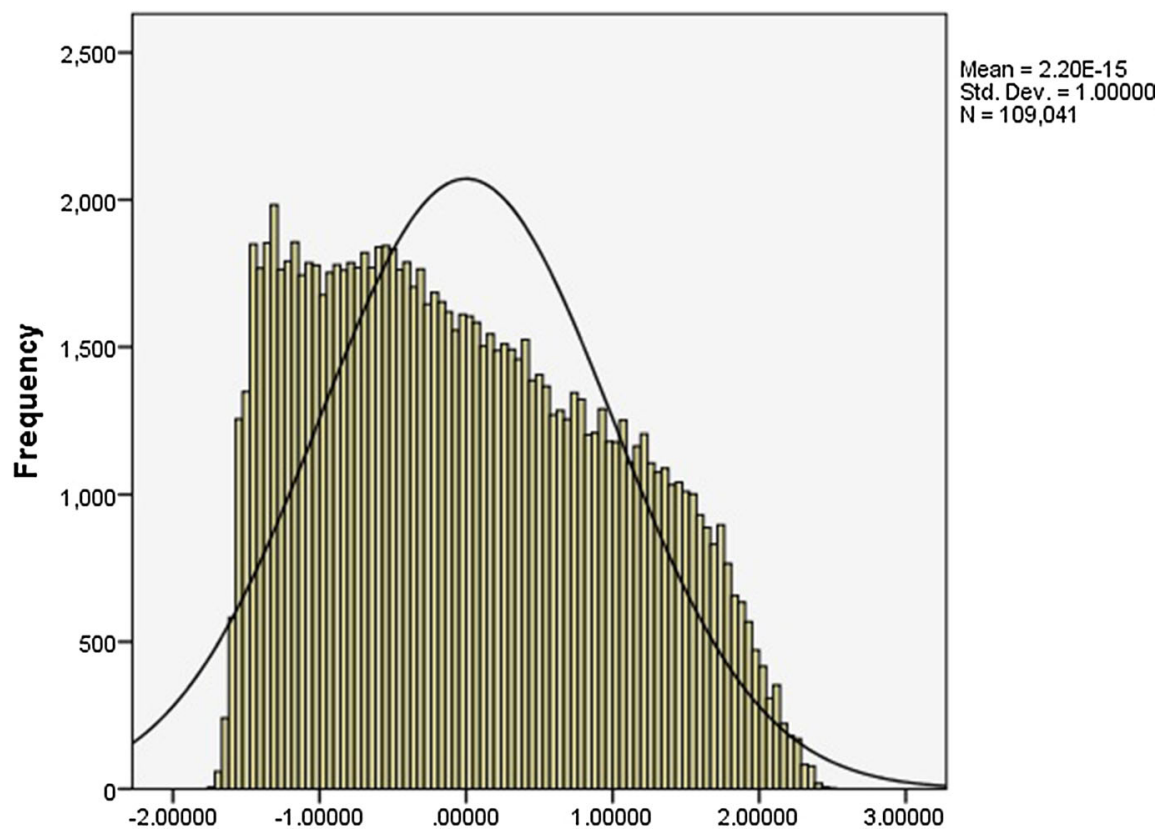

Fig. 1 Distribution of households by Standard of Living Index

\section{Results}

We report regression results in Table 5. We present an unrestricted model (Model 1 in Table 5), and a restricted version (Model 2 in Table 5). In the restricted version, we drop the gender and the house variables. ${ }^{5}$

Table 5 indicates the importance of female literacy rates. The coefficient on female literacy rates suggests that as the level of education increases, women are more likely to adopt a toilet. The odds ratio for households in which a woman has attained a higher education is 3.1 times more in comparison with households where a woman has attained education till the preschool level. Our result is consistent with Wei et al. (2004) and Ghosh and Cairncross (2014) stressing the need for female literacy rates.

We find, as the number of women in any household increases, that household is less likely to adopt a toilet. The gender variable is also not statistically significant. Results from Jenkins and Curtis (2005) and Santos et al. (2011) indicate otherwise. Women are more likely to adopt better sanitation practices than men due to perceived benefits of greater dignity and safety. In fact, the Sanitation Quality, Use, Access and Trends (SQUAT) survey, 2014, conducted in Bihar, Haryana, Madhya Pradesh, Uttar Pradesh, and Rajasthan, find women are more likely to use toilets than men.

\footnotetext{
5 The predictive power of Model 2 gets increased when we drop these two variables. For selecting models, we use Akaike Information Criteria (AIC). Given a number of potential models, the model with the lowest AIC value was chosen.
} 
Table 5 Use of toilets conditional on household characteristics

\begin{tabular}{|c|c|c|c|}
\hline Characteristic & Variable & Model 1 & Model 2 \\
\hline \multirow[t]{4}{*}{ Womens education } & Intercept & $-1.363 * * *$ & $-1.464 * * *$ \\
\hline & Primary & $0.159 * * *$ & $0.160 * * *$ \\
\hline & Secondary & $0.535 * * *$ & $0.535 * * *$ \\
\hline & Higher & $1.130 * * *$ & $1.130 * * *$ \\
\hline Number of women in the household & Women & $-0.167 * * *$ & $-0.168 * * *$ \\
\hline \multirow[t]{5}{*}{ Type of Residence } & Megacity & $3.534 * * *$ & $3.547 * * *$ \\
\hline & Large city & $2.954 * * *$ & $2.966 * * *$ \\
\hline & Small city & $1.785 * * *$ & $1.792 * * *$ \\
\hline & Largetown & $1.888 * * *$ & $1.891 * * *$ \\
\hline & Small town & $1.025 * * *$ & $1.029 * * *$ \\
\hline \multirow[t]{3}{*}{ Wealth variables } & House & -0.102 & - \\
\hline & Hectare & $0.011 * *$ & 0.011 \\
\hline & Bank & $0.192 * * *$ & $0.190 * * *$ \\
\hline Standard of Living Index & & $2.029 * * *$ & $2.031 * * *$ \\
\hline Infrastructure & Water availability & $0.563 * * *$ & $0.561 * * *$ \\
\hline \multirow[t]{6}{*}{ Household head } & Muslim & $1.695 * * *$ & $1.695 * * *$ \\
\hline & Christian & $0.229 * *$ & $0.227 * *$ \\
\hline & Other religion & $0.537 * * *$ & $0.540 * * *$ \\
\hline & Caste & $-0.255^{* * *} *$ & $-0.253 * * *$ \\
\hline & Gender & -0.029 & - \\
\hline & Age & $0.004 * * *$ & $0.004 * * *$ \\
\hline \multirow[t]{17}{*}{ State dummies } & Jammu \& Kashmir & $-0.746 * * *$ & $-0.746^{* * *}$ \\
\hline & Himachal Pradesh & -0.197 & -0.183 \\
\hline & Punjab & $0.470 * *$ & $0.480 * *$ \\
\hline & Uttaranchal & $0.827 * * *$ & $0.833 * * *$ \\
\hline & Haryana & 0.097 & 0.098 \\
\hline & Rajasthan & $-0.453^{* *}$ & $-0.455^{* *}$ \\
\hline & UttarPradesh & $0.389 * *$ & $0.386 * *$ \\
\hline & Bihar & $0.831 * * *$ & $0.837 * * *$ \\
\hline & Sikkim & $3.689 * * *$ & $3.690 * * *$ \\
\hline & Arunchal Pradesh & $4.121 * * *$ & $4.140 * * *$ \\
\hline & Nagaland & $3.885^{* * *}$ & $3.903 * * *$ \\
\hline & Manipur & $4.721 * * *$ & $4.723 * * *$ \\
\hline & Mizoram & $5.647 * * *$ & $5.654 * * *$ \\
\hline & Tripura & $6.626 * * *$ & $6.635 * * *$ \\
\hline & Meghalaya & $3.321 * * *$ & $3.323 * * *$ \\
\hline & Assam & $3.703 * * *$ & $3.705 * * *$ \\
\hline & West Bengal & $2.564 * * *$ & $2.565 * * *$ \\
\hline
\end{tabular}


Table 5 continued

\begin{tabular}{llll}
\hline Characteristic & Variable & Model 1 & Model 2 \\
\hline Jharkhand & -0.061 & -0.063 \\
Orissa & 0.309 & 0.312 \\
Chhattisgarh & -0.008 & -0.01 \\
Madhya Pradesh & $0.536 * * *$ & $0.538^{* * *}$ \\
Gujarat & 0.316 & 0.319 \\
Maharashtra & 0.062 & 0.066 \\
Andhra Pradesh & $0.649 * * *$ & $0.655 * * *$ \\
& Karnataka & $0.357 *$ & $0.361 *$ \\
& Goa & $0.889 * * *$ & $0.900 * * *$ \\
& Kerala & $3.844 * * *$ & $3.847 * * *$ \\
Tamil Nadu & -0.249 & -0.25 \\
\hline & LR test statistics & $\chi^{2}(47)=64.00 * * *$ & $\chi^{2}(45)=61.66 * * *$ \\
\hline
\end{tabular}

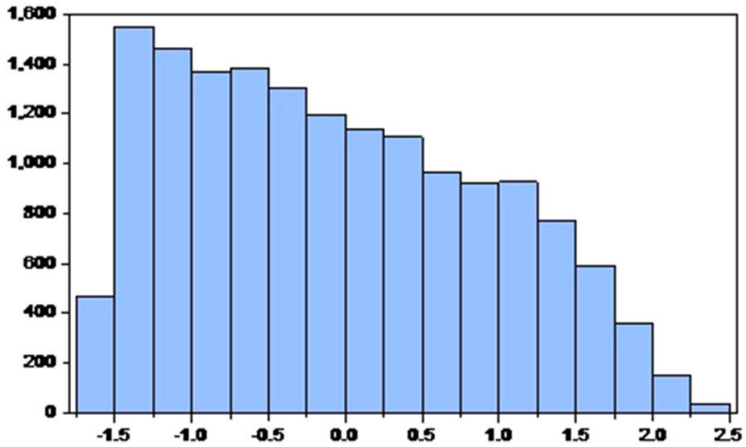

Series: DURABLE_DWELLINGINDEX Sample 1109041 IF GENDER=1 Observations 15709

Mean $\quad-0.071023$

Median $\quad-0.183990$

Maximum 2.376280

Minimum $\quad-1.690440$

Std. Dev. $\quad 0.984820$

Skewness $\quad 0.327160$

Kurtosis $\quad 2.048187$

Jarque-Bera $\quad 873.2131$

Probability $\quad 0.000000$

Fig. 2 Histogram of Standard of Living scores where the household head is a Female

However, we have explanations for this result. Verick (2014) find low work participation rates among women in India. Therefore, on an average, households with more number of women are also the households with a lower living standard. We find households with woman as head member has more number of female members $(2.8$ women per household) in comparison with households with men as head member (2.2 women per household). In fact, households with woman as head member have a lower mean standard of living index score in comparison with the households headed by men, -0.071 (for female) compared to 0.012 (for male) (See, Figs. 2, 3). With more number of poor female family members, there is a likelihood that the household may not have a toilet.

Households with a better standard of living are likely to own toilets more than the ones who are poor. Our model predicts that the odds of owning a toilet becomes 7.6 times higher if standard of living index variable increases by 1 unit. A richer 

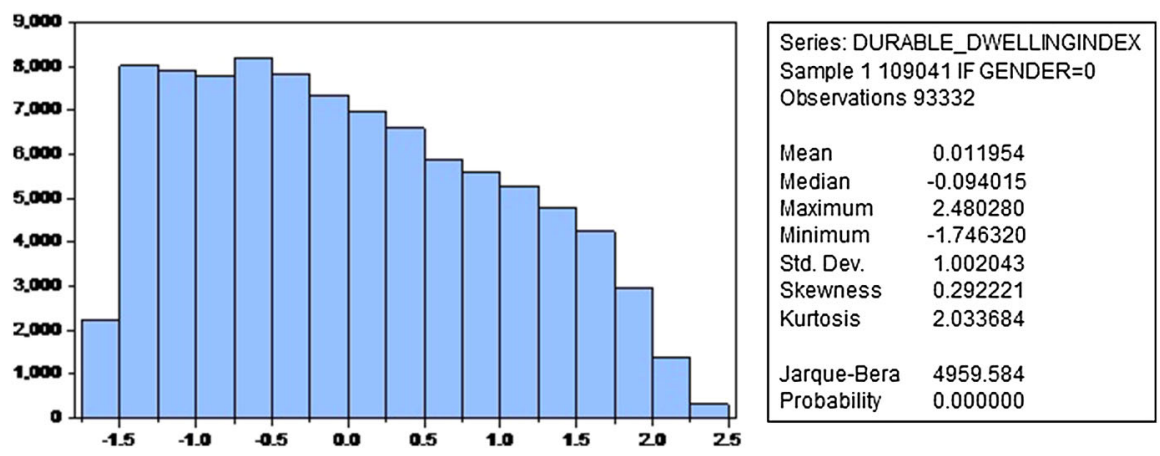

Fig. 3 Histogram of Standard of Living scores where the household head is a Male

household with a pucca house ${ }^{6}$ is more likely to have toilets. Research by Dickinson and Pattanayak (2007) yields similar findings, with correlation between housing characteristics such as type of walls and ownership of toilets. Halder and Kabir (2008) demonstrated that the absence of a toilet facility is linked to a lower socio-economic status (based on household assets, housing conditions, etc.) in Bangladesh.

We find that urban households are more likely to have toilets in comparison with their rural counterparts. In comparison with rural areas, the odds for having toilets in mega cities such as Mumbai and Kolkata are nearly 35 times higher. The odds ratio for households having toilets in small cities, in turn is higher than ones residing in small towns. And all these urban-odd ratios are higher than the odd ratios computed for the rural areas. A household in a small town is 2.8 times more likely to have a toilet than his counterpart from rural areas. Our findings is similar to that of Bonu and Kim (2009) who demonstrate that the rural-urban differential in household possession of latrines has remained large over the past decade_diminishing slightly from $62 \%$ in 1992-1993 to 57.8\% in 2004-2005. According to the National Sample Survey report (Government of India 2015), while $87.9 \%$ of the urban households were found to have access to water for use in toilets, only $42.5 \%$ rural households had this facility. Banerjee and Banik (2014) show for $1 \%$ increase in a closed drainage system, the income increases between 0.96 and $2.58 \%$.

The Planning Commission, Government of India (2002) has cited two reasons as to why urbanization might lead to more toilets coverage. First is the higher concentration and construction of toilet facilities in urban areas are facilitated by government-private initiatives, which is not so prevalent in rural areas. Second is because of other factors such as lower awareness about possible health benefits, higher levels of poverty, beliefs that owning a household toilets have higher costs, and a simple lack of modernization could be a barrier to improved sanitation in rural areas.

The positive sign on the coefficient of agricultural land (Hectare variable) indicates that as number of units of agricultural land holding increases, the household becomes wealthier and is more likely to own toilets. This finding is similar to Salter (2008) and O'Connell (2014). Additionally, the odds ratio for households that own a bank or post

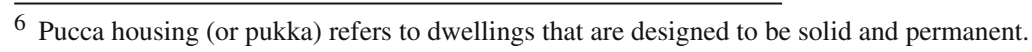


office account is 1.2 times more likely to have a toilet than the ones who do not have access to these amenities. Wealthier people not only have better access to financial institutions but are also more likely to own toilets.

Then there is religion factor affecting use of toilets. In terms of odds, the religion variables demonstrate that Muslim households are 5.4 times more likely to adopt a toilet than a Hindu household is. Even a Christian household is 1.3 times more likely to adopt a toilet in comparison with their Hindu counterparts. Using DHS data, Bonu and Kim (2009) obtained a similar result, with the Hindu households having the lowest coverage of sanitation facilities in comparison with other religions.

This result is surprising, as Indian Muslims are on average are poorer than the Hindus (Bhalotra et al. 2010). The example from Bangladesh (a predominantly Muslim dominated country) suggests a reason for superior sanitation rate in the former in comparison with that of India is because culturally Muslims are accustomed to offering prayer (azan) five times a day. And, each time they do, they have a practice of washing their hands and feet, and physically cleaning themselves. Muslim women are more likely to adopt better sanitation practices in comparison with their male counterparts due to the perceived benefits of dignity and safety. However, Hazra and Dutta (2016) find that Muslims are generally less averse to owning and using affordable toilets which need to have their pits emptied every few years than Hindus.

The coefficient of the Caste variable predicted by Model 2 is -0.253 , implies that Scheduled Caste (SC), Scheduled Tribe (ST) and Other Backward Class (OBC) households have a lower probability of using toilets when compared with households from general caste Hindu, Muslims, and Christians. Srinivasan and Mohanty (2004) have found that the level of abject poverty is higher among these castes, which could be a potential reason for poorer sanitation coverage among SC, ST, and OBCs.

Finally is the state-level variance in the coverage of toilets. The odds ratio for households in the north-eastern Indian States of Manipur, Mizoram, Tripura, Meghalaya etc., and the southern state of Kerala having toilets are much higher than a household in Delhi (the reference state). For example, a household in Tripura is 761.5 times more likely to have toilets than a household in Delhi. The state dummies for Rajasthan, Jammu \& Kashmir, Himachal Pradesh, Jharkhand, Chhattisgarh, and Tamil Nadu have negative coefficients implying that the probability of households using toilets in these states is lower than in Delhi. Such findings have been observed in previous academic literature as well, with the backward states of Rajasthan, Jharkhand, and Chhattisgarh having lower levels of toilets coverage in comparison with other states (Coffey et al. 2014). For Tamil Nadu — a Hindu dominated state-the reason for its poor performance on sanitation could be attributed to the cultural factor. Ramaswamy (2005) and Bathran (2011) argue that open defecation among Hindu households is due to caste system, where the customary circumvention of excreta is sustained by keeping defecation away from the house and entrusting the clean-up job to the socalled untouchables or 'lower' castes. To sum up, even after controlling for the usual socio-economic factors like caste, religion, education, women-empowerment, wealth, and access to water, we find that state-level variation exists. The main reason for open defecation is behaviour and mindset of the people who have continued this practice of defecating in the open for centuries. 
Table 6 Use of toilets conditional on rural household characteristics

\begin{tabular}{|c|c|c|c|}
\hline Type of variable & Variable & Model 1 & Model 2 \\
\hline \multirow[t]{4}{*}{ Womens education } & Intercept & $-0.711 * *$ & $-0.700 * *$ \\
\hline & Primary & $0.172 * * *$ & $0.172 * * *$ \\
\hline & Secondary & $0.566 * * *$ & $0.565 * * *$ \\
\hline & Higher & $1.117 * * *$ & $1.116^{* * *}$ \\
\hline Number of women & Women & $-0.155^{* * *}$ & $-0.155^{* * *}$ \\
\hline \multirow[t]{6}{*}{ Household head type } & Gender & -0.045 & - \\
\hline & Age & $0.005 * * *$ & $0.005 * * *$ \\
\hline & Muslim & $1.679 * * *$ & $1.678 * * *$ \\
\hline & Christian & $0.333 * * *$ & $0.332 * * *$ \\
\hline & Other_religion & $0.575 * * *$ & $0.574 * * *$ \\
\hline & Caste & $-0.195^{* * *}$ & $-0.195^{* * *}$ \\
\hline \multirow[t]{3}{*}{ Wealth variables } & House & -0.016 & - \\
\hline & Hectare & $0.012 * *$ & $0.013 * *$ \\
\hline & Bank & $0.238 * * *$ & $0.238 * * *$ \\
\hline Standard of Living Index & Durable_Dwelling & $1.966 * * *$ & $1.966 * * *$ \\
\hline Infrastructure & Water availability & $0.665 * * *$ & $0.613 * * *$ \\
\hline \multirow[t]{23}{*}{ State dummies } & Jammu and Kashmir & $-1.452 * * *$ & $-1.453 * * *$ \\
\hline & Himachal Pradesh & $-1.082 * * *$ & $-1.091 * * *$ \\
\hline & Punjab & -0.394 & -0.396 \\
\hline & Uttaranchal & -0.068 & -0.073 \\
\hline & Haryana & $-0.802 * * *$ & $-0.803^{* * *}$ \\
\hline & Rajasthan & $-1.517 * * *$ & $-1.516^{* * *}$ \\
\hline & UttarPradesh & $-0.537 *$ & $-0.538^{*}$ \\
\hline & Bihar & -0.026 & -0.033 \\
\hline & Sikkim & $2.754 * * *$ & $2.754 * * *$ \\
\hline & Arunchal Pradesh & $3.154 * * *$ & $3.152 * * *$ \\
\hline & Nagaland & $2.827 * * *$ & $2.826 * * *$ \\
\hline & Manipur & $3.661 * * *$ & $3.660 * * *$ \\
\hline & Mizoram & $4.590 * * *$ & $4.588 * * *$ \\
\hline & Tripura & $5.669 * * *$ & $5.669 * * *$ \\
\hline & Meghalaya & $2.247 * * *$ & $2.245 * * *$ \\
\hline & Assam & $2.734 * * *$ & $2.734 * * *$ \\
\hline & West Bengal & $1.761 * * *$ & $1.761 * * *$ \\
\hline & Jharkhand & $-1.430 * * *$ & $-1.432 * * *$ \\
\hline & Orissa & $=-0.517 *$ & $=-0.519 *$ \\
\hline & Chhattisgarh & $-0.979 * * *$ & $-0.979 * * *$ \\
\hline & Madhya Pradesh & -0.414 & -0.412 \\
\hline & Gujarat & $=-0.578 *$ & $=-0.576^{*}$ \\
\hline & Maharashtra & $-0.895 * * *$ & $-0.894 * * *$ \\
\hline
\end{tabular}


Table 6 continued

\begin{tabular}{llll}
\hline Type of variable & Variable & Model 1 & Model 2 \\
\hline Andhra Pradesh & -0.324 & -0.324 \\
Karnataka & $-0.580 * *$ & $=-0.582 *$ \\
Goa & 0.134 & 0.126 \\
Kerala & $2.959 * * *$ & $2.960 * * *$ \\
Overall significance & TamilNadu & $-1.129 * * *$ & $-1.131 * * *$ \\
& LR test statistics & $\chi^{2}=58.12$ & $\chi^{2}=55.76$ \\
\hline
\end{tabular}

To check robustness of our results and also that the literature indicates that the rural households are prone to open defecation, we do a sub-sample analysis with only rural households. The coefficient of a variable originally considered is robust if its sign and level of significance do not change. Considering rural households only, we find that our results are consistent with the previous analysis. The results are shown in Table 6.

\section{Conclusions and policy implications}

There are a number of policy implications. First, governments from developing countries, India in particular, should concentrate on creation of demand for using toilets. They must ensure that a larger proportion of funds are directed towards IEC component of the policy. The lesson from the Nirmal Gram Yojana experience suggests cash incentives will not necessarily increase awareness to use toilets. Rather than counting the number of toilets being built, the approach should be about tracking region-wise number of open defecators. Not only is monitoring required but introduction of more programmes in the line of TSC is expected to be fruitful.

Second, empirical analysis indicates female literacy rate is an important factor. Use of toilets can be improved by policies that aim to emancipate and increase education levels among women. Empowering women through increase labour force participation will put emphasis on owning and using toilets.

Third, there is a rural-urban divide, with sanitation problem concentrated in rural parts of India. There is a need for government policies specifically focusing on improving sanitation in rural areas.

Fourth, the religion and caste-based differentials in adoption of toilets are more difficult to eradicate. Religion and caste-based differentials are rooted in some ingrained beliefs and attitudes. To change this behavioural attitude, the government needs to recast its effort to communicate the benefits of not defecating in the open.

A limitation of this study is that we have not considered the market demand for toilet. It will be interesting to consider factors, such as the price for providing a toilet. Additionally, a more encompassing income and wealth variables will be useful to evaluate if sanitation subsidies that target the poor have actually reached the intended groups. These variables will enable construction of a precise demand function for a toilet. 
Open Access This article is distributed under the terms of the Creative Commons Attribution 4.0 International License (http://creativecommons.org/licenses/by/4.0/), which permits unrestricted use, distribution, and reproduction in any medium, provided you give appropriate credit to the original author(s) and the source, provide a link to the Creative Commons license, and indicate if changes were made.

\section{References}

Banerjee AN, Banik N (2014) Is India shining? Rev Dev Econ 18(1):59-72

Banerjee T, Mandal K (2011) Revisiting the Midnapore model after ten years of total sanitation campaign (TSC) in India. SSRN Working Paper. http://ssrn.com/abstract=1768687

Bathran R (2011) Indian sanitation. Econ Polit Wkly XLVI:34-37

Bhalotra S, Valente C, van Soest A (2010) The puzzle of Muslim advantage in child survival in India. J Health Econ 29:191-204

Bonu S, Kim H (2009) Sanitation in India: progress, differentials, correlates and challenges. Asian Development Bank, South Asia Occasional Paper Series No. 2

Coffey D, Gupta A, Hathi P, Khurana N, Spears D, Srivastav N, Vyas S (2014) Revealed preference for open defecation: evidence from a new survey in rural North India. Econ Polit Wkly XLIX(38):43-55

Dickinson K, Pattanayak S (2007) Open sky latrines: do social interactions influence decisions to use toilets? Duke University, Working Paper. http://aae.wisc.edu/events/papers/DevEcon/2008/dickinson.09.25. pdf

Filmer D, Pritchett LH (2001) Estimating wealth effects without expenditure data-or tears: an application to educational enrollments in states of India. Demography 38(1):115-132

Ghosh A, Cairncross S (2014) The uneven progress of sanitation in India. J Water Sanit Hyg Dev 4(1): 15-22

Government of India, Planning Commission (2002) India assessment 2002: water supply and sanitation, 2002, a WHO-UNICEF sponsored study. Planning Commission, Delhi. http://planningcommission. gov.in/reports/genrep/wtrsani.pdf

Government of India (2015) Houselisting and housing census data-2011. http://www.censusindia.gov.in/ 2011census/hlo/HLO_Tables.html

Halder AK, Kabir M (2008) Child mortality inequalities and linkage with sanitation facilities in Bangladesh. J Health Popul Nutr 26(1):64-73

Hazra G, Dutta A (2016) The gap between construction and usage of toilets: an under-identified problem. BMJ Glob Health A39(1):A2-A43

Jenkins MW, Curtis V (2005) Achieving the 'good life': why some people want latrines in rural Benin. Soc Sci Med 61(11):2446-2459

J-PAL (2012) J-PAL urban services review paper. Abdul LatifJameel Poverty Action Lab, Cambridge

O'Connell K (2014) What influences open defecation and latrine ownership in rural households? Findings from a global review. Water and Sanitation Program, Working Paper, World Bank, Washington

O'Reilly K, Louis E (2014) The toilet tripod: understanding successful sanitation in rural India. Health Place 29:43-51

OECD (2013) OECD guidelines for micro statistics on household wealth. OECD Publishing. http://www. oecd.org/statistics/OECD-Guidelines-for-Micro-Statistics-on-Household-Wealth.pdf

Ramani SV (2008) Playing in invisible markets: toilet innovations and empowerment. The Charles Cooper Annual Memorial Lecture, UNU-MERIT Working Paper Series

Ramaswamy G (2005) India stinking: manual scavengers in Andhra Pradesh and their work. Navayana Publishing, Chennai

Salter D (2008) Identifying constraints to increasing sanitation coverage: sanitation demand and supply in Cambodia. Water and Sanitation Program. http://www.wsp.org/sites/wsp.org/files/publications/ Sanitation_demand_and_supply_fieldnote_final__1.pdf

Santos AC, Roberts JA, Barreto ML, Cairncross S (2011) Demand for sanitation in Salvador, Brazil: a hybrid choice approach. Soc Sci Med 72(8):1325-1332

Shah A, Thathachari J, Agarwal R, Karamchandani A (2013) A market led, evidence based, approach to rural sanitation. Monitor Inclusive Markets, on behalf of The Bill \& Melinda Gates Foundation

Spears D (2012) Health and cognitive achievement among Indian children. Econ Human Biol 10(2):210-219

Srinivasan K, Mohanty SK (2004) Deprivation of basic amenities by caste and religion: empirical study using NFHS data. Econ Polit Wkly 39(7):728-735 
UNICEF (2012) An overview of status of drinking water and sanitation in schools in India. UNICEF WASH. http://in.one.un.org/img/uploads/Snapshot_WASH\%20in\%20Schools_India_v2.pdf

Verick S (2014) Women's labour force participation in India? Why is it so low? ILO DWT, South Asia, New Delhi

Wei F, Pillai V, Maleku A (2004) Sanitation in India: role of women's education. Health Sci J 8(1):90-101

WHO and UNICEF (2014) Progress on drinking water and sanitation: 2014 update. World Health Organisation, Geneva. http://www.wssinfo.org/fileadmin/user_upload/resources/JMP_report_2014_webEng. pdf 